UNDERGROUND MINING ENGINEERING 34 (2019) 27-41 $\quad$ UDK 62

\title{
SENSITIVITY ANALYSIS OF ROCK MASS PARAMETERS ESTIMATE INFLUENCE ON DECLINE SUPPORT DESIGN USING NATM
}

\author{
Slavko Torbica ${ }^{1}$, Veljko Lapčević ${ }^{1}$, Wang Gang ${ }^{2}$, Nemanja Đokić ${ }^{1}$, Miodrag \\ Duranović
}

Received: May 18, 2019

Accepted: June 21, 2019

\begin{abstract}
:
Capital mine development is often faced with limited geotechnical databases and designers are faced with more or less accurate estimates of missing parameters. GSI classification if often used with numerical modelling and its rounding unit is \pm 5 as suggested by its creators. In situ stresses are usually estimated in such manner that vertical component is equal to the weight of the rocks above, while horizontal components may vary in wide range, starting with ratio to vertical component of 0.3 and even be several times higher than vertical component.

Influence of estimate error of GSI and horizontal stress is analyzed for the Cukaru Peki location near Bor in Serbia. Zone in the rock mass valued with GSI of 40 at depth $160 \mathrm{~m}$ is analyzed for the change of GSI value of \pm 5 and horizontal stress ratio between 0.5-1.5. Change of the unsupported length of decline and shotcrete layer thickness is tracked for different values of input parameters. Finally, best case and worst case scenarios are analyzed with results showing that shotcrete layer thickness could vary in range between $4-33 \mathrm{~cm}$, and unsupported lengths between 0.6-2m.
\end{abstract}

Keywords: Rock mass; Tunneling; NATM; GSI; Stress; Cukaru Peki; Bor;

\section{INTRODUCTION}

Design of the underground openings requires that crucial data about rock mass conditions should be determined, such as its strength, deformability and stress conditions that are present. Strength and deformability of the rock masses are commonly determined by classification systems such as Q (Barton et al., 1974), RMR (Bienawski, 1993) or GSI (Hoek, 1994). GSI is commonly used due to its applicability in numerical codes and possibility to determine it by limited database. However, this implies possible errors in determination and consequences that may occur.

\footnotetext{
${ }^{1}$ University of Belgrade - Faculty of Mining and Geology

${ }^{2}$ Rakita Exploration d.o.o. Bor, Suvaja Street 185A, 19210 Bor, Serbia

Emails:torbica@rgf.bg.ac.rs;veljko.lapcevic@ @rgf.bg.ac.rs;wang.gang@ rakita.net; nemanja.djokic@rgf.rs; miodrag.duranovic@rgf.rs;
} 
Stress filed is also one of crucial parameters that influence the stability and design of support for underground openings. Vertical stress component is generally equal to the weight of the above lying rock masses, while horizontal stress components are usually expressed as fraction of the vertical component. Terzaghi and Richart (1952) suggested method to determine horizontal stress ratio by relation $\frac{v}{1-v}$ which estimates it to around 50\% of the vertical stress intensity. Numerous works (Zhang et al., 2012; Torbica and Lapčević, 2016) point out that horizontal stresses may be several times higher than those estimate using only Terzaghi's approach and that previous method is insuficient.

Herein, sensitivity analysis for the Cukaru Peki near Bor, Serbia site is analyzed by variation of the possible GSI and stress ratio values. Intention is to emphasize the influence that misjudgment of these parameters can have on advancement of excavation and support design.

\section{METHODOLOGY}

Decline is meant to be excavated down to the depth of almost $600 \mathrm{~m}$ and along its trajectory passes through several weak zones. One of such weak zones is expected to be passed at the depth of the $160 \mathrm{~m}$. This zone is estimated to be around $120 \mathrm{~m}$ long and passes through the jointed and weak sandstone layer. Rock mass properties of this zone are shown in Table 1.

Table 1 Initially estimated rock mass properties in the analyzed zone

\begin{tabular}{ll}
\hline Parameter & Estimated value \\
\hline Compressive strength & $50 \mathrm{MPa}$ \\
Young's modulus & $28 \mathrm{GPa}$ \\
Poisson's ratio & 0.3 \\
GSI & 37 \\
\hline
\end{tabular}

Decline cross section is given in Figure 1 and total cross sectional area is around $25 \mathrm{~m}^{2}$. 


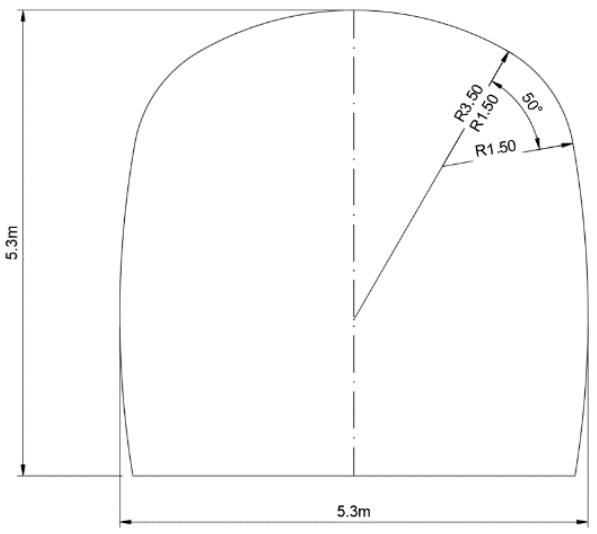

Figure 1 Decline cross section

Estimated GSI value of 37 (as given by geologist who logged the exploratory cores) is always just estimate and engineers should be aware of possible error of this estimate. Analysis herein is performed for 3 different GSI values of 35, 40 and 45 since these are estimated to be possible margins of error that is easy to made.

Initial stress condition are not know and therefore are estimated in such way that gravitational component is equal to the weight of above laying rock mass. Horizontal components are changed between $0.5-1.5^{*}$ gravitational component in order to assess the model sensitivity to the actual stress state in to emphasize its importance. Orientation of the horizontal stresses is such that one component is perpendicular to the decline trajectory meaning that second component is aligned with decline trajectory.

As summary, GSI and stress value estimate error is tested for the impact on support and advancement step of decline development.

Analysis is based on the parameters given in Table 2 and Table 3 .

Table 2 Rock mass parameters used in analyses

\begin{tabular}{llll}
\hline \multirow{2}{*}{ Parameters } & \multicolumn{3}{c}{ GSI } \\
\cline { 2 - 4 } & \multicolumn{2}{c}{35} & \multicolumn{2}{c}{40} \\
\hline$\sigma_{\mathrm{ci}}(\mathrm{MPa})$ & 50 & 50 & 50 \\
$\mathrm{E}_{\mathrm{i}}(\mathrm{MPa})$ & 28000 & 28000 & 28000 \\
$\mathrm{E}_{\mathrm{m}}(\mathrm{MPa})$ & 3175 & 4470 & 6260 \\
Poisson's ratio & 0.3 & 0.3 & 0.3 \\
$\mathrm{~m}_{\mathrm{i}}$ & 19 & 19 & 19 \\
$\mathrm{~m}_{\mathrm{b}}$ & 1.865 & 2.229 & 2.665 \\
$\mathrm{~s}$ & 0.00073 & 0.001 & 0.002 \\
\hline
\end{tabular}


Table 3 Stress data used in analysis

\begin{tabular}{lccc}
\hline \multirow{2}{*}{$\begin{array}{c}\text { Stress } \\
\text { components }\end{array}$} & 0.5 & $\mathrm{k}$ & \\
\cline { 2 - 4 }$\sigma_{1}(\mathrm{MPa})$ & $4.32 *$ & 4.32 & 6.48 \\
$\sigma_{2}(\mathrm{MPa})$ & 2.16 & 4.32 & 6.48 \\
$\sigma_{3}(\mathrm{MPa})$ & 2.16 & 4.32 & $4.32 *$ \\
\hline *vertical & & &
\end{tabular}

\subsection{FEM model}

Methodology used herein is based on the research proposed by Vlachopoulos and Diederichs (2009) that made it possible to estimate 3D progression of the underground opening with utilization of 2D FEM models. This method was originally developed for the circular shaper of the tunnels/drifts, however it has been shown to be applicable for other shapes of the underground openings. Main advantage of this method is that is eliminates complex 3D numerical modeling and reducing time necessary for analysis while providing results reliable enough.

FEM model is created using Phase 2 software by Rocscience (2019) and has 20 stages. At the internal boundary of excavation distributed load is applied (Figure 2), where in the first stage this load is equal to the field stress and at every stage it is being decreased for $5 \%$ of initial load. In final stage complete distributed load is removed and plain stress strain state is simulated. In this manner progressive excavation is simulated.

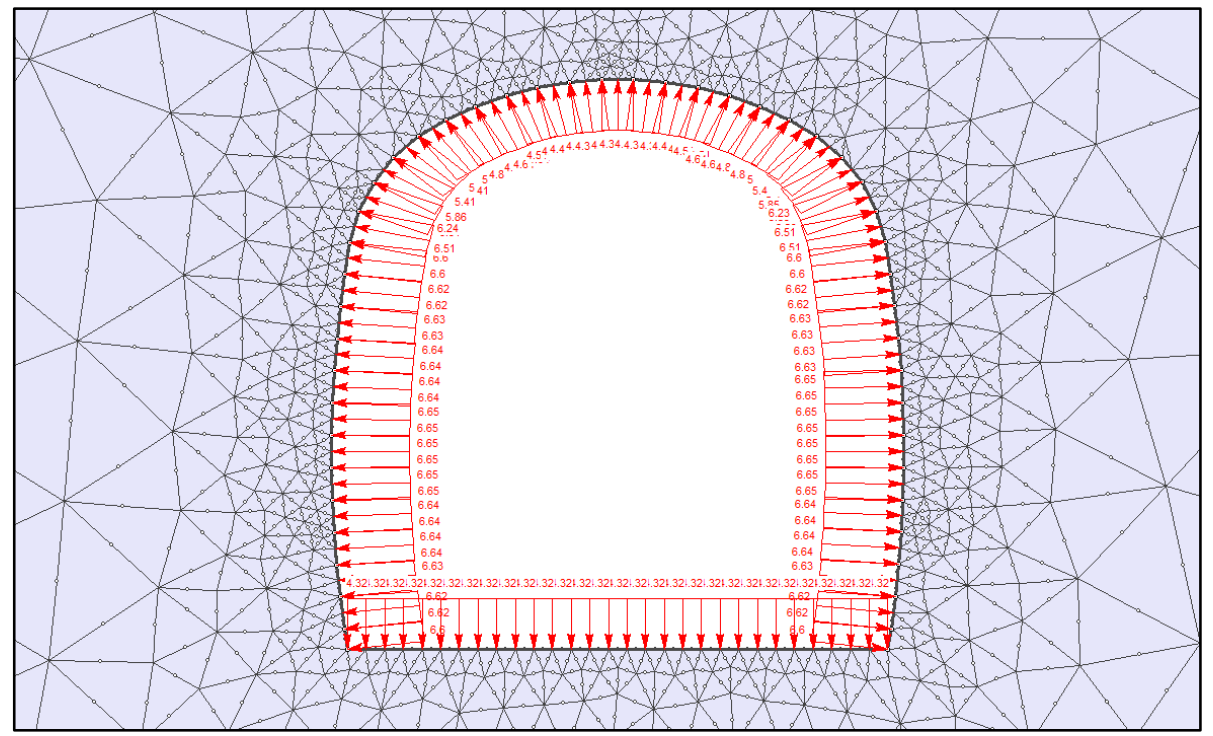

Figure 2 Distributed load at excavation boundary 
After model convergence it is necessary to determine radius of plasticization around the underground opening (Figure 3) as well as deformation diagram for point with largest total displacement (Figure 4).

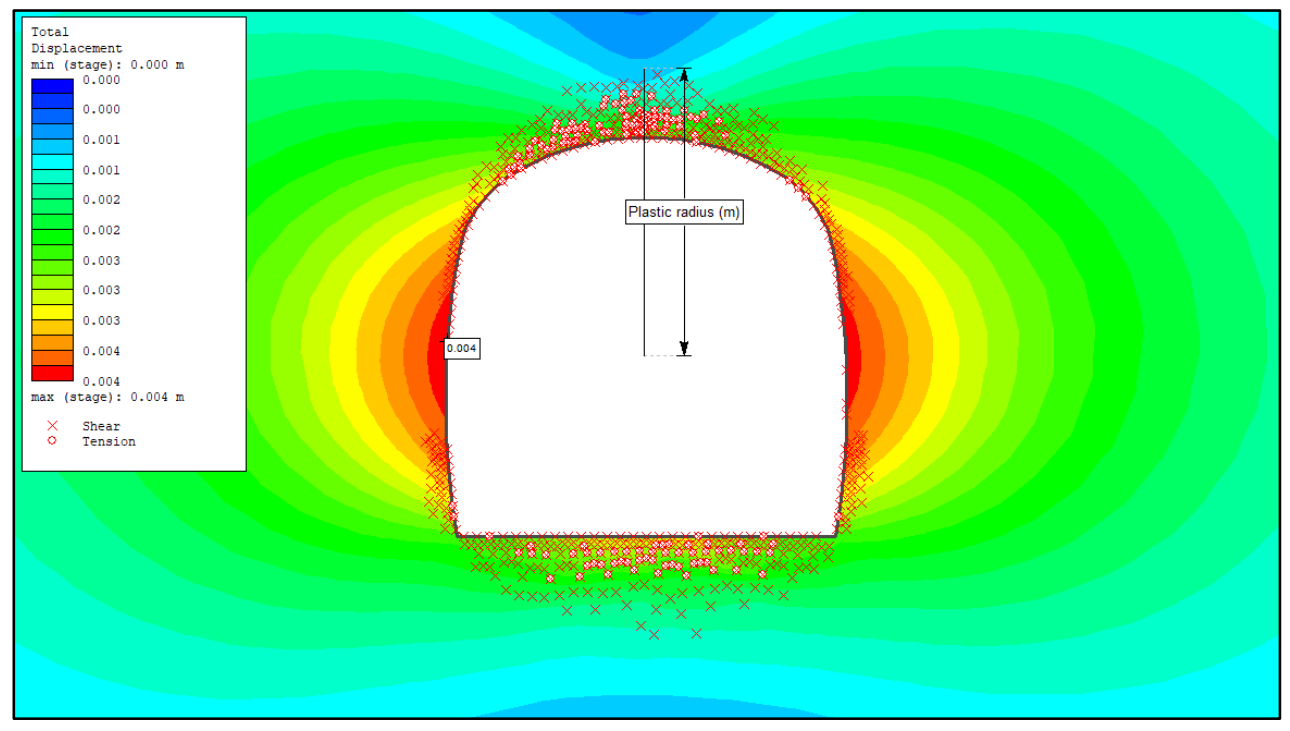

Figure 3 Plastic radius and total displacement in final stage of the model

Main principle is to determine longest unsupported length of the decline, or, put in other words, distance between supported part of decline and its face. Therefore, in FEM model we are determining the stage before failure of the rock mass occurs as it is illustrated in Figure 4. It is important to mark down the total displacement value in this stage since it is necessary for the next step of the procedure.

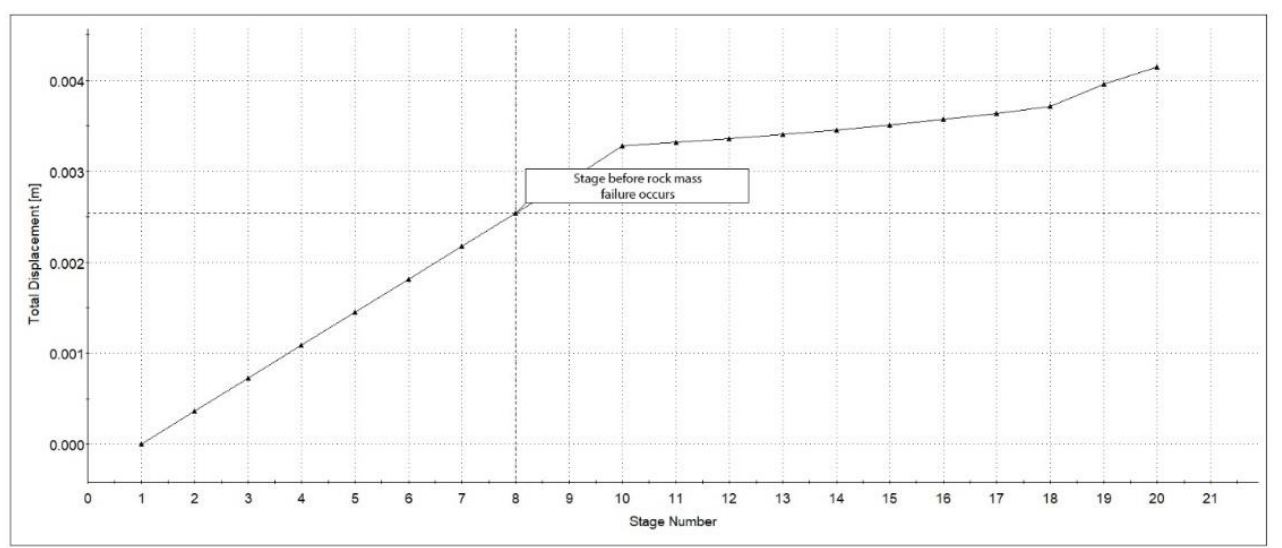

Figure 4 Deformation diagram for the point with largest total displacement 
By knowing the ratio between the total displacement in the stage before the failure of the rock mass occurs and the maximum displacement (Closure to maximum closure as illustrated in Figure 5) we are using the diagram created by Vlachopoulos and Diederichs (2009) to determine the unsupported length of decline.

Diagram curves (Figure 5) represent the ratio between plastic zone radius and decline radius. For example if we determine following values:

\section{Closure $/$ maximum closure $=0.8$}

Plastic zone radius / decline radius $=1.5$

Then we read from the diagram:

Distance from decline face $/$ decline radius $=1.3$

Finally, unsupported length of the decline is:

Distance from decline face $=1.3^{*}$ decline radius

This procedure is repeated for each case.

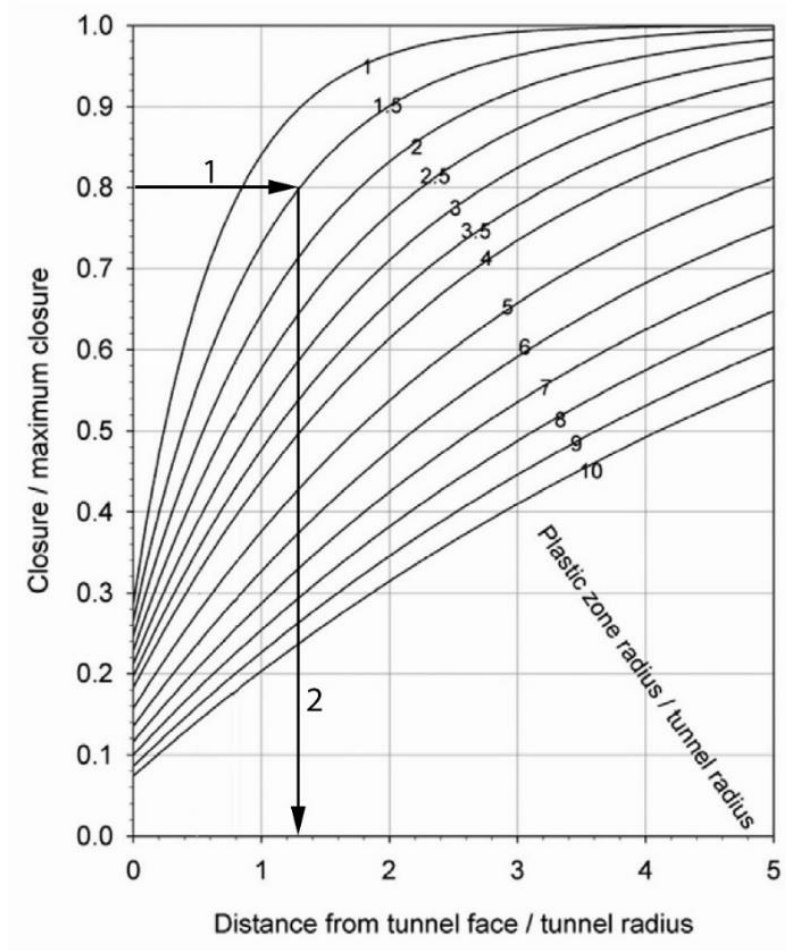

Figure 5 Diagram by Vlachopoulos and Diederichs (2009) 
Determining the unsupported length of decline is first part of the analysis, second one is to determine necessary support for the decline. For simplicity, only thickness of the shotcrete layer is determined for the required FOS=1.4.

Support design procedure assumes that shotcrete layer is installed in the stage of FEM model before the failure of the rock mass, stage that has been determine in previous analysis. In each case same properties of shotcrete layer are used as shown in Table 4.

Table 4 Shotcrete properties used for the analysis

\begin{tabular}{ll}
\hline Parameter & \\
\hline Young's modulus & $30000 \mathrm{MPa}$ \\
Poisson ratio & 0.15 \\
Compressive strength & $30 \mathrm{MPa}$ \\
Tensile strength & $3 \mathrm{MPa}$ \\
\hline
\end{tabular}

\section{RESULTS}

\subsection{GSI error influence}

As it was originally suggested by the Hoek (2007) GSI value should be rounded by increments of 5, meaning that value of GSI $=37$ that was initially estimated should be 35 or 40. Herein, it is assumed that initial GSI value is 40 and with consideration of the possible estimate error it can spread in span between 35-45. Therefore, there GSI=35, 40 and 45 values are analyzed.

Change of the GSI influences change of the rock mass strength properties for the HoekBrown's failure criteria and deformation modulus (estimated by Hoek and Diedrich (2006)). Change of these parameters influences support loading as well as size of the plastic zone around underground opening.

All the stress components are equal $\left(\sigma_{v}=\sigma_{H}=\sigma_{h}=4.32 \mathrm{MPa}\right)$. Intensity corresponds to the intensity of the gravitational component for the depth of $160 \mathrm{~m}$ assuming that average unit weight is $0.027 \mathrm{MN} / \mathrm{m}^{3}$.

Analysis results are presented in Figure 6, Figure 7 and Table 5. It is seen that decreasing GSI value determines lower unsupported lengths ranging from $1.4 \mathrm{~m}$ to $0.6 \mathrm{~m}$. Roughly talking unsupported length of the decline is around $1 \mathrm{~m}$ and it determines the advancements and excavation organization. If we compare extreme values, it implies that advance of $1.4 \mathrm{~m}$ is more than doubled compared with $0.6 \mathrm{~m}$, meaning that twice as much time and costs are necessary to develop decline in worse conditions. 
Table 5 Analysis results

\begin{tabular}{|c|c|c|c|}
\hline \multirow{2}{*}{ Parameters } & \multicolumn{3}{|c|}{ GSI } \\
\hline & 45 & 40 & 35 \\
\hline Tunnel radius, Rt (m) & 2.8 & 2.8 & 2.8 \\
\hline Plastic zone radius, $\mathrm{Rp}(\mathrm{m})$ & 3.25 & 3.8 & 3.8 \\
\hline $\mathrm{Rp} / \mathrm{Rt}$ & 1.16 & 1.36 & 1.36 \\
\hline Maximum closure, $\mathrm{u}_{\max }(\mathrm{m})$ & 0.0030 & 0.0064 & 0.0110 \\
\hline Closure in support installation stage, $\mathrm{u}(\mathrm{m})$ & 0.0018 & 0.0034 & 0.0047 \\
\hline $\mathrm{u} / \mathrm{u} \max$ & 0.60 & 0.53 & 0.43 \\
\hline Distance from face / tunnel radius & 0.5 & 0.4 & 0.2 \\
\hline Distance from face & 1.4 & 1.1 & 0.6 \\
\hline
\end{tabular}

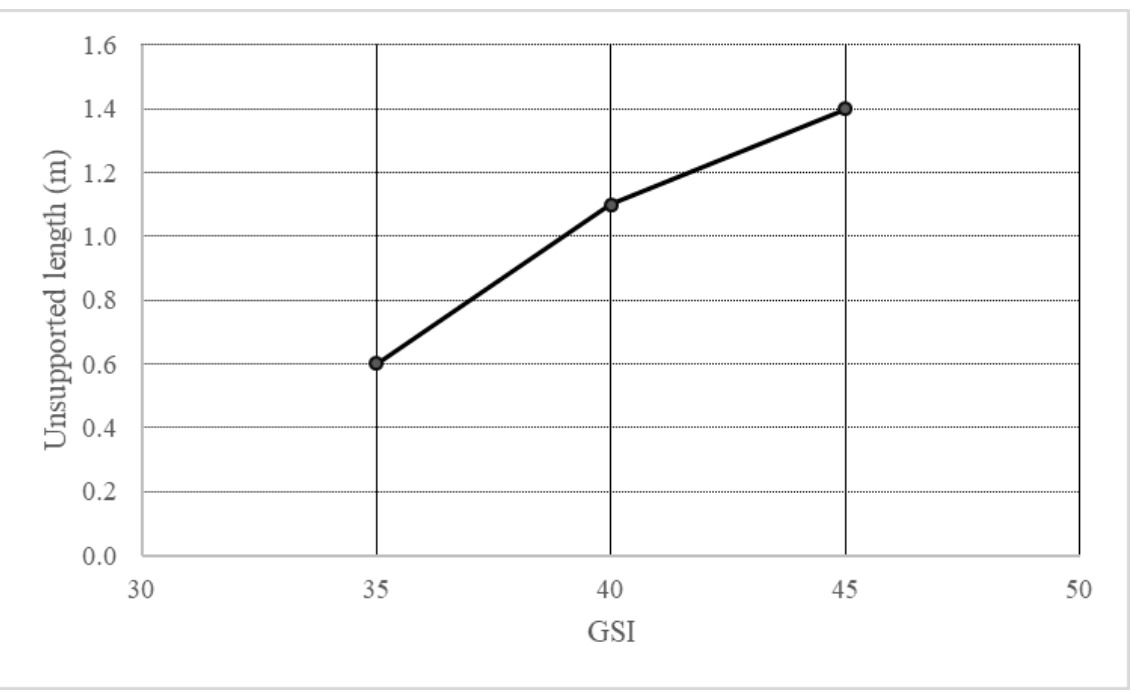

Figure 6 Unsupported length vs GSI change

Figure 7 illustrates change of the necessary shotcrete thickness for different GSI values. It is seen that for the lowest GSI value of 35 shotcrete layer with the FOS $=1.4$ has thickness of $9 \mathrm{~cm}$, while in the case of GSI=45 shotcrete layer with same FOS has thickness of $4 \mathrm{~cm}$. It is clear that amount of support that is necessary in these cases is enormous. Considering differences in advancements that could be achieved it is obvious that costs may be significantly different. 


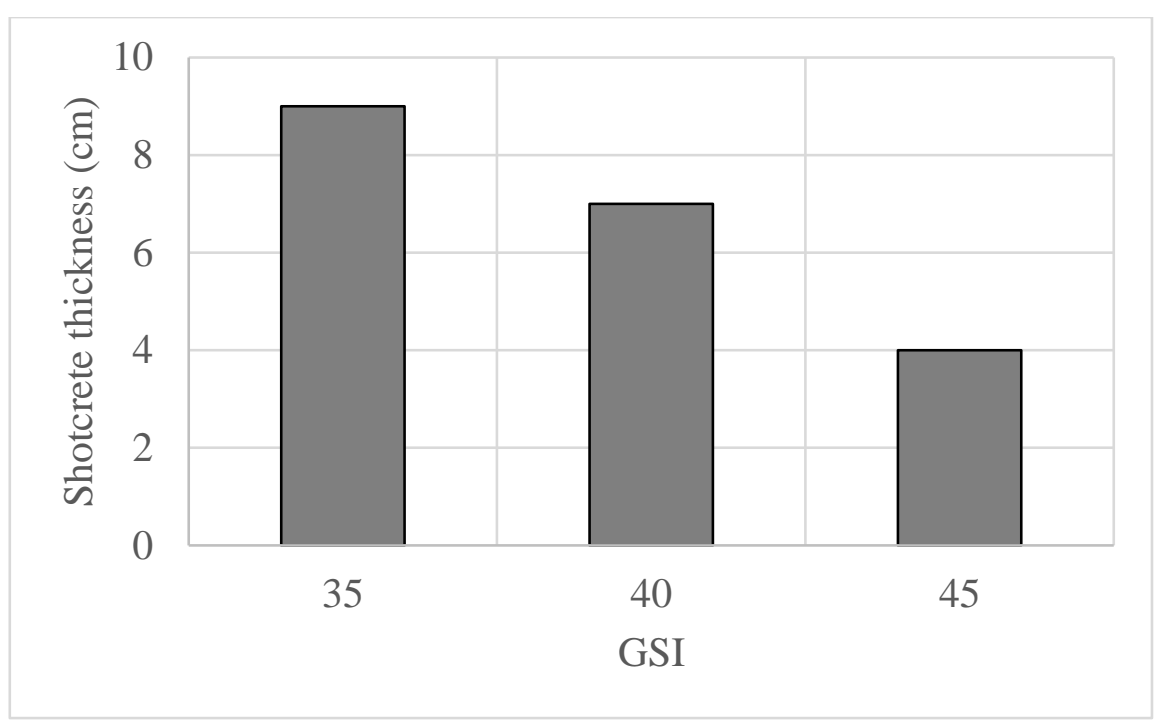

Figure 7 Shotcrete thickness vs GSI change

\subsection{Horizontal stress influence}

Common approach in geomechanical analyses is that horizontal stress is expressed as portion of the gravitational stress component. Horizontal component often estimated by the expression $\frac{v}{1-v}$ which estimates horizontal stress between $30-50 \%$ of the vertical component depending on actual Poisson's ratio value. However, horizontal stress ratio is know to be higher than this (1-1.5) especially at shallow depths. Zhang et al. (2012) provided useful estimate for the different rock types.

Analysis herein is done for 3 different stress ratios $(0.5,1$ and 1.5$)$ with equal minor and major horizontal components. Rock mass parameters are taken for the average GSI value of 40. Results are given in Table 6, Figure 8 and Figure 9. 
Table 6 Analysis results

\begin{tabular}{llll}
\hline \multirow{2}{*}{\multicolumn{1}{c}{ Parameters }} & \multicolumn{3}{c}{$\mathrm{k}$} \\
\cline { 2 - 4 } & \multicolumn{1}{c}{0.5} & \multicolumn{1}{c}{1} & \multicolumn{1}{c}{1.5} \\
\hline Tunnel radius, Rt (m) & 2.8 & 2.8 & 2.8 \\
Plastic zone radius, Rp (m) & 3.9 & 3.8 & 4.13 \\
Rp / Rt & 1.39 & 1.36 & 1.47 \\
Maximum closure, $\mathrm{u}_{\max }(\mathrm{m})$ & 0.0053 & 0.0064 & 0.010 \\
Closure in support installation stage, $\mathrm{u}(\mathrm{m})$ & 0.0034 & 0.0034 & 0.0046 \\
u / umax & 0.64 & 0.53 & 0.46 \\
Distance from face / tunnel radius & 0.7 & 0.4 & 0.3 \\
Distance from face & 2 & 1.1 & 0.8 \\
\hline
\end{tabular}

As it is seen, unsupported length of decline decreases with the increasing horizontal stresses as it could have been expected. In case when horizontal stress is $50 \%$ of the vertical component is possible to achieve advance of $2 \mathrm{~m}$ before support installation and roof collapse. Unsupported length drops significantly for ratios 1 and 1.5 and is around $1 \mathrm{~m}$.

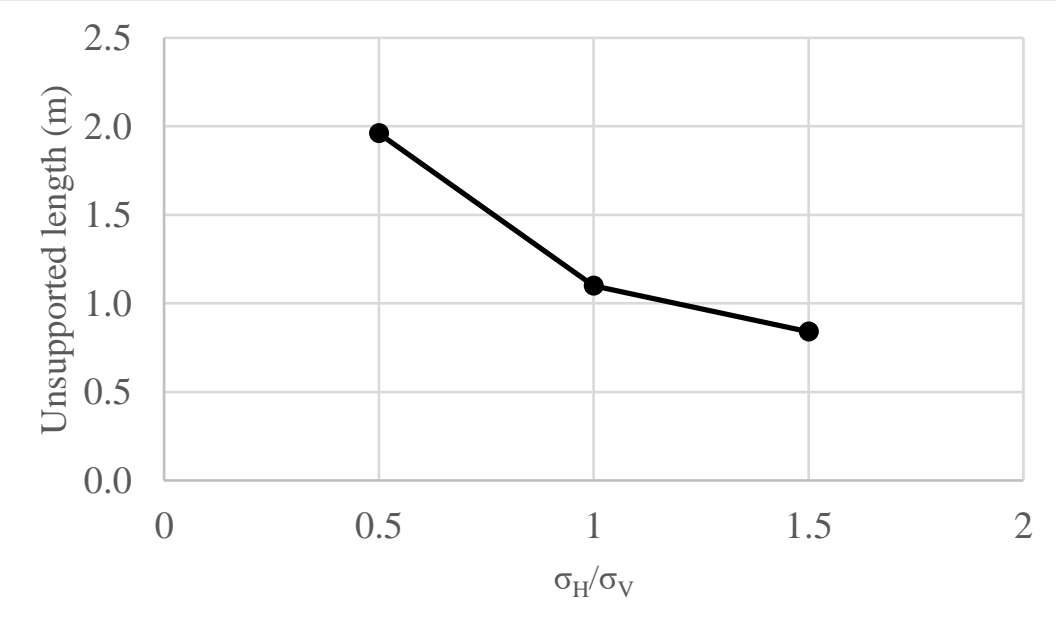

Figure 8 Unsupported length vs stress ratio

For the previously determined unsupported lengths shotcrete thickness is determined using explained methodology. In the case of highest thickness of the shotcrete layer with the FOS $=1.4$ is $15 \mathrm{~cm}$ while for the case where stress ratio is 1 shotcrete layer is $7 \mathrm{~cm}$ thick. This illustrates the stress influence on the needed support. 
For the case where stress ratio $=0.5$ shotcrete layer is $10 \mathrm{~cm}$ thick. This comes from the fact that in this case unsupported length of the underground opening is almost 2 times higher than in previously discussed cases.

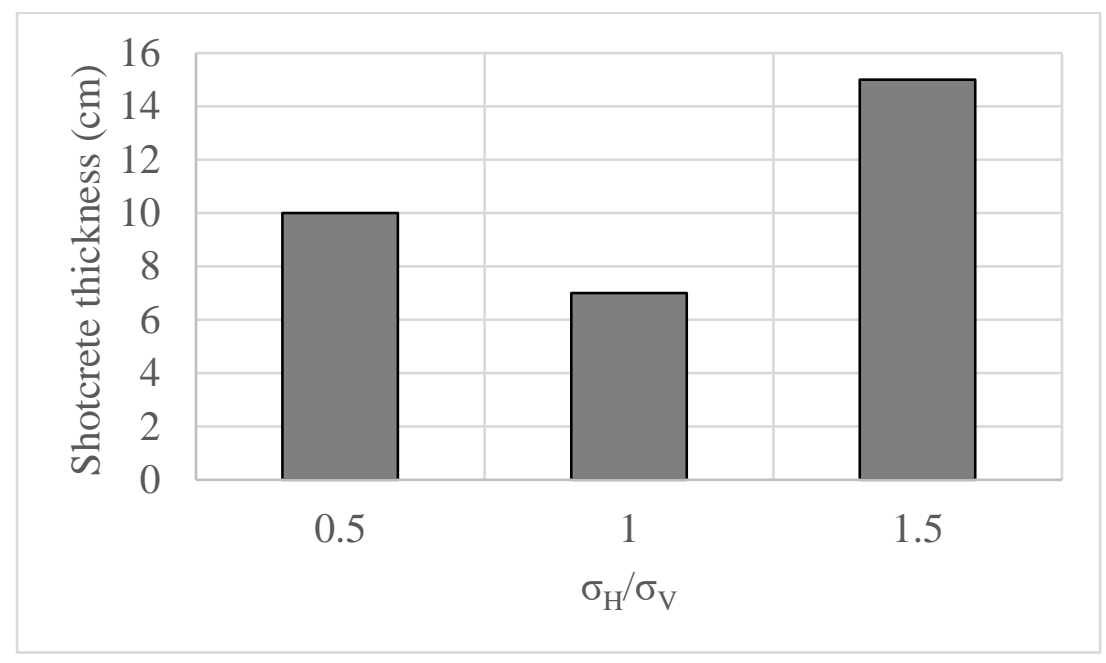

Figure 9 Shotcrete thickness vs stress ratio

\subsection{Best- and worst-case scenarios}

As it was shown in previous sections, possible estimate errors in stress and GSI values may have high impact on excavation advancing and required support. Intention is to illustrate range of possible outcomes and to point out what dangers are lying under deterministic selection of analysis parameters without testing the sensitivity of their influence.

In best-case scenario it is like to assume that rock mass is stronger than estimated and that stresses are low. Therefore, in our case this would mean that rock mass has GSI of 45 and that horizontal stress ratio is 0.5 .

For the worst-case scenario we would like to assume that rock mass is weaker than initially estimated and that stress ratio is higher. In our case this would mean that GSI value is 35 while horizontal stress ratio is 1.5 .

Results presented in Table 7, Figure 10 and Figure 11 show that two cases may differ significantly. If most favorable conditions are experienced unsupported length of the underground opening can be around $2 \mathrm{~m}$ and shotcrete layer with FOS=1.4 has thickness of $4 \mathrm{~cm}$. 
On the other side, if lower strength and higher stress are to be present unsupported length of the underground opening is significantly reduced to $0.6 \mathrm{~m}$. Shotcrete layer thickness is dramatically increased to $33 \mathrm{~cm}$ in order to maintain desired FOS.

Table 7 Analysis results

\begin{tabular}{lll}
\hline \multicolumn{1}{c}{ Parameters } & Worst & \multicolumn{1}{c}{ Best } \\
\hline Tunnel radius, $\mathrm{Rt}(\mathrm{m})$ & 2.8 & 2.8 \\
Plastic zone radius, $\mathrm{Rp}(\mathrm{m})$ & 4.7 & 3.75 \\
$\mathrm{Rp} / \mathrm{Rt}$ & 1.68 & 1.34 \\
Maximum closure, $\mathrm{u}_{\max }(\mathrm{m})$ & 0.015 & 0.0027 \\
Closure in support installation stage, $\mathrm{u}(\mathrm{m})$ & 0.0062 & 0.0018 \\
$\mathrm{u} / \mathrm{u}_{\max }$ & 0.41 & 0.67 \\
Distance from face / tunnel radius & 0.2 & 0.7 \\
Distance from face & 0.6 & 2 \\
\hline
\end{tabular}

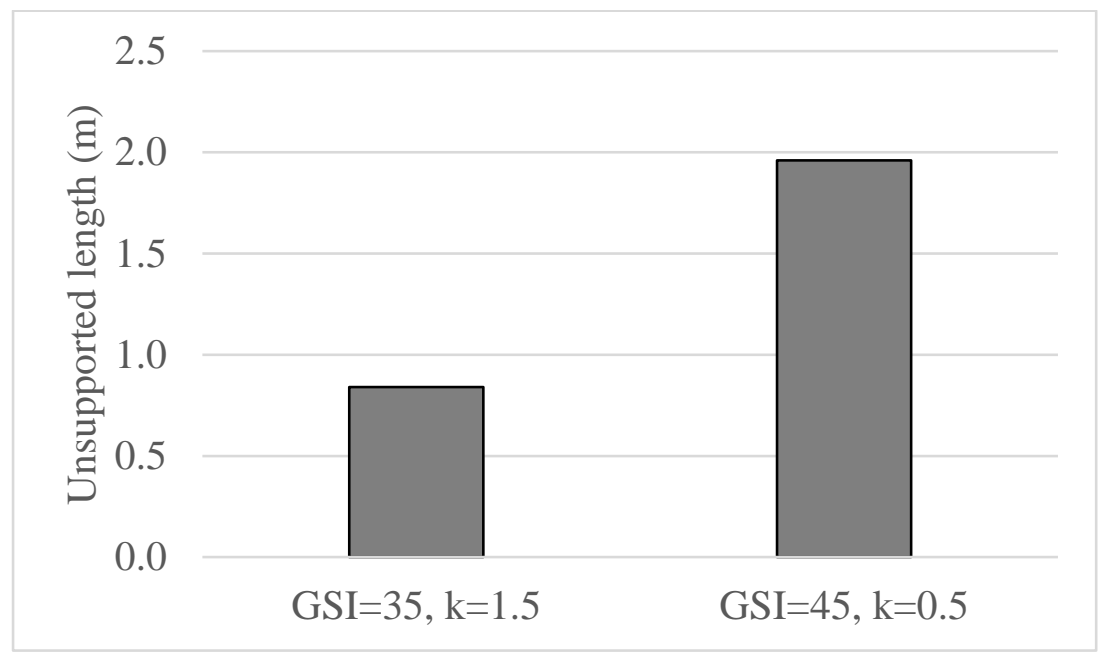

Figure 10 Unsupported length vs stress ratio 


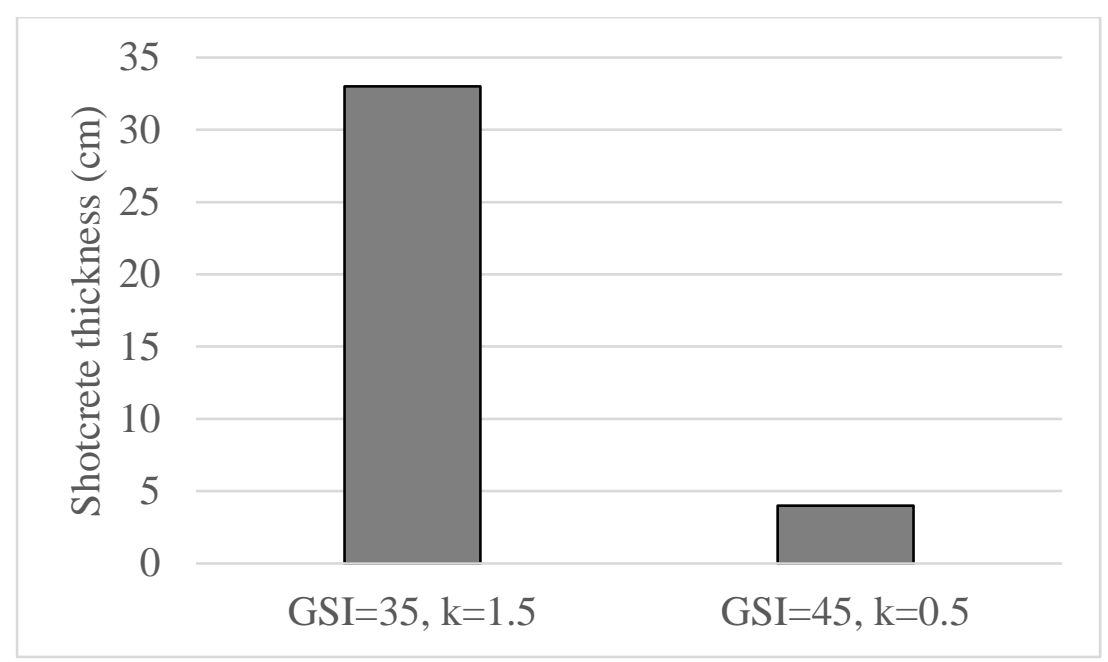

Figure 11 Shotcrete thickness fro best- and worst-case

\section{CONCLUSION}

Analysis herein was undertaken in order to emphasize the importance of sensitivity analysis of crucial parameters for design of the underground openings. Geological strength index is commonly estimated in increments of 5 and therefore its estimation is highly subjective. Range of GSI values \pm 5 of the estimated value is possible error that could be made. It is not unusual that horizontal stress components are not treated with care they require, especially in mining applications.

Results show that GSI change influences both unsupported length of decline as well as thickness of the shotcrete layer. With increasing GSI value from 35 to 45 unsupported length increases from $0.6 \mathrm{~m}$ to $1.4 \mathrm{~m}$, while required shotcrete layer thickness ranges from $4 \mathrm{~cm}$ to $9 \mathrm{~cm}(F O S=1.4)$ for corresponding lengths. Major reason for these changes comes from the estimate of the deformation modulus of the rock mass that is directly related to GSI.

Stress change was analyzed by changing the ratio between horizontal and vertical components from 0.5 to 1.5 , while rock mass strength and deformability parameters were kept constant (GSI=40). Unsupported length goes from $2 \mathrm{~m}$ in case of the ratio of 0.5 to $0.8 \mathrm{~m}$ in case when stress ratio is 1.5 . For case with ratio of 0.5 shotcrete layer thickness is $10 \mathrm{~cm}(\mathrm{FOS}=1.4)$ while in the case of ratio of 1.5 thickness is $15 \mathrm{~cm}$. In case where stress ratio is 1 shotcrete layer is $7 \mathrm{~cm}$ thick, but this comes from the fact that unsupported length is $1.1 \mathrm{~m}$ and should not be misinterpreted if compared with the case with lowest stress ratio. 
In best case where strength of the rock mass is the highest and the stresses are lowest it is shown that unsupported length is around $2 \mathrm{~m}$ and necessary shotcrete thickness is $4 \mathrm{~cm}$. on the other side, in worst possible case unsupported length is $0.6 \mathrm{~m}$ with shotcrete layer of $33 \mathrm{~cm}$.

By comparing best and worst possible cases it is clear that possible estimated errors could lead in serious misjudgments about necessary support and advancing of excavation. Other implications may include delays and work safety issues, as well as planning of required materials.

\section{Acknowledgement}

Authors would like to acknowledge RAKITA d.o.o. for approval and availability of geotechnical database for Cukaru Peki location near Bor.

\section{REFERENCES}

BARTON, N. et al. (1974) Engineering classification of rock masses for the design of tunnel support. Rock mechanics, 6(4), pp.189-236.

BIENIAWSKI, Z.T. (1993) Classification of rock masses for engineering: the RMR system and future trends. In: Rock Testing and Site Characterization, Pergamon, pp. 553- 573.

HEIDBACH O. et al. (2008) The 2008 release of the World Stress Map. [Online] Available from: http://www.world-stress-map.org. [Accessed 5/5/2019]

HOEK, E. (1994) Strength of rock and rock masses. ISRM News Journal, pp. 4-16.

HOEK, E. (2007) Practical Rock Engineering. Rocscience Inc.

HOEK, E and DIEDERICHS, M. (2006) Empirical estimates of rock mass modulus. International Journal of Rock Mechanics and Mining Sciences, 43, pp. 203-215

ROCSCIENCE INC. (2019) Phase2 Version 9.0 - Finite Element Analysis for Excavations and Slopes. Toronto, Ontario, Canada.

TERAGHI, K. and RICHART, F.E. (1952) Stresses in Rock About Cavities. Géotechnique, 3 (2), pp. 57-90.

TORBICA, S. and LAPČEVIĆ, V. (2016) Model for estimation of stress field in the Earth's crust. Podzemni Radovi, (28), pp. 9-17. 
Sensitivity analysis of rock mass parameters...

VLACHOPOULOS, N. and DIEDERICHS, M.S. (2009) Improved Longitudinal Displacement Profiles for Convergence Confinement Analysis of Deep Tunnels. Rock Mechanics and Rock Engineering, 42(2), pp. 131-146.

ZANG, A. et al. (2012) World stress map database as a resource for rock mechanics and rock engineering. Geotechnical and Geological Engineering, 30(3), pp.625-646. 